\title{
Review Article \\ Biomarkers in Posttraumatic Stress Disorder: Overview and Implications for Future Research
}

\author{
Ulrike Schmidt, Sebastian F. Kaltwasser, and Carsten T. Wotjak
}

Max Planck Institute of Psychiatry, Kraepelinstrasse 10, 80804 Munich, Germany

Correspondence should be addressed to Ulrike Schmidt; uschmidt@mpipsykl.mpg.de

Received 10 March 2013; Accepted 15 April 2013

Academic Editor: Daniel Martins-de-Souza

Copyright (c) 2013 Ulrike Schmidt et al. This is an open access article distributed under the Creative Commons Attribution License, which permits unrestricted use, distribution, and reproduction in any medium, provided the original work is properly cited.

\begin{abstract}
PTSD can develop in the aftermath of traumatic incidents like combat, sexual abuse, or life threatening accidents. Unfortunately, there are still no biomarkers for this debilitating anxiety disorder in clinical use. Anyhow, there are numerous studies describing potential PTSD biomarkers, some of which might progress to the point of practical use in the future. Here, we outline and comment on some of the most prominent findings on potential imaging, psychological, endocrine, and molecular PTSD biomarkers and classify them into risk, disease, and therapy markers. Since for most of these potential PTSD markers a causal role in PTSD has been demonstrated or at least postulated, this review also gives an overview on the current state of research on PTSD pathobiology.
\end{abstract}

\section{Introduction}

Traumatic stressors are existence threatening events like accidents, combat, or sexual abuse which may lead to PTSD, an incapacitating anxiety disease with the core symptoms nervous hyperarousal, distressing recalls of traumatic memories, and avoidance of trauma-related cues [1]. The likelihood of developing PTSD depends inter alia on the population studied. For example, Kessler and colleagues reported a PTSD lifetime prevalence of $6.8 \%$ for the United States (USA) [2] while Maercker and coworkers found Germany's PTSD lifetime prevalence to be much lower (i.e., 2.3\% [3]). Amongst other factors, varying occurrence rates of traumatic events and employment of different diagnostic instruments contribute to these international differences in PTSD prevalence. In any case, most individuals do not develop PTSD or any other trauma spectrum disorder after trauma exposure. The probability to develop PTSD depends on individual risk and resilience factors and increases with the number of traumatic events experienced [4] as well as with the stress intensity of the traumatic incidents [5]. There is much evidence that social factors like the extent of familiar support [6], psychological factors such as cognitive reappraisal and optimism [7], and biological factors like epigenetic markers [8], single nucleotide polymorphisms (SNPs) [9], endocrine factors [10], and neurotransmitter systems [11] modulate PTSD susceptibility, progression of PTSD, and probably also the response to PTSD treatment.

PTSD susceptibility biomarkers would be especially useful for prevention in professions at high risk for trauma exposure like combat soldiers and firefighters. Ideally, PTSD susceptibility markers should identify individuals at high risk for PTSD in order to prevent them from being exposed (primary prevention) or, if exposure already happened, to care for a timely initiation of a preventive therapy before manifestation of PTSD symptoms (secondary prevention).

A biomarker is defined as a process, substance, or structure that can be measured in the body or its products in order to analyze the risk to develop a certain disease, to diagnose a disease, to assess disease progress and prognosis, to predict the outcome of various treatment options before their application, or to determine treatment efficacy [12]. Like any biomarker, also PTSD biomarkers should fulfill certain requirements in terms of reliability (i.e., they have to be robust enough to be inert to repetitive testing and slight variations in analysis procedures), specificity (i.e., they have to have discriminatory power among different disorders), and cost efficacy (e.g., particular imaging tools are too cost intensive to be employed for high throughput identification of susceptibility markers). An overview of the different 


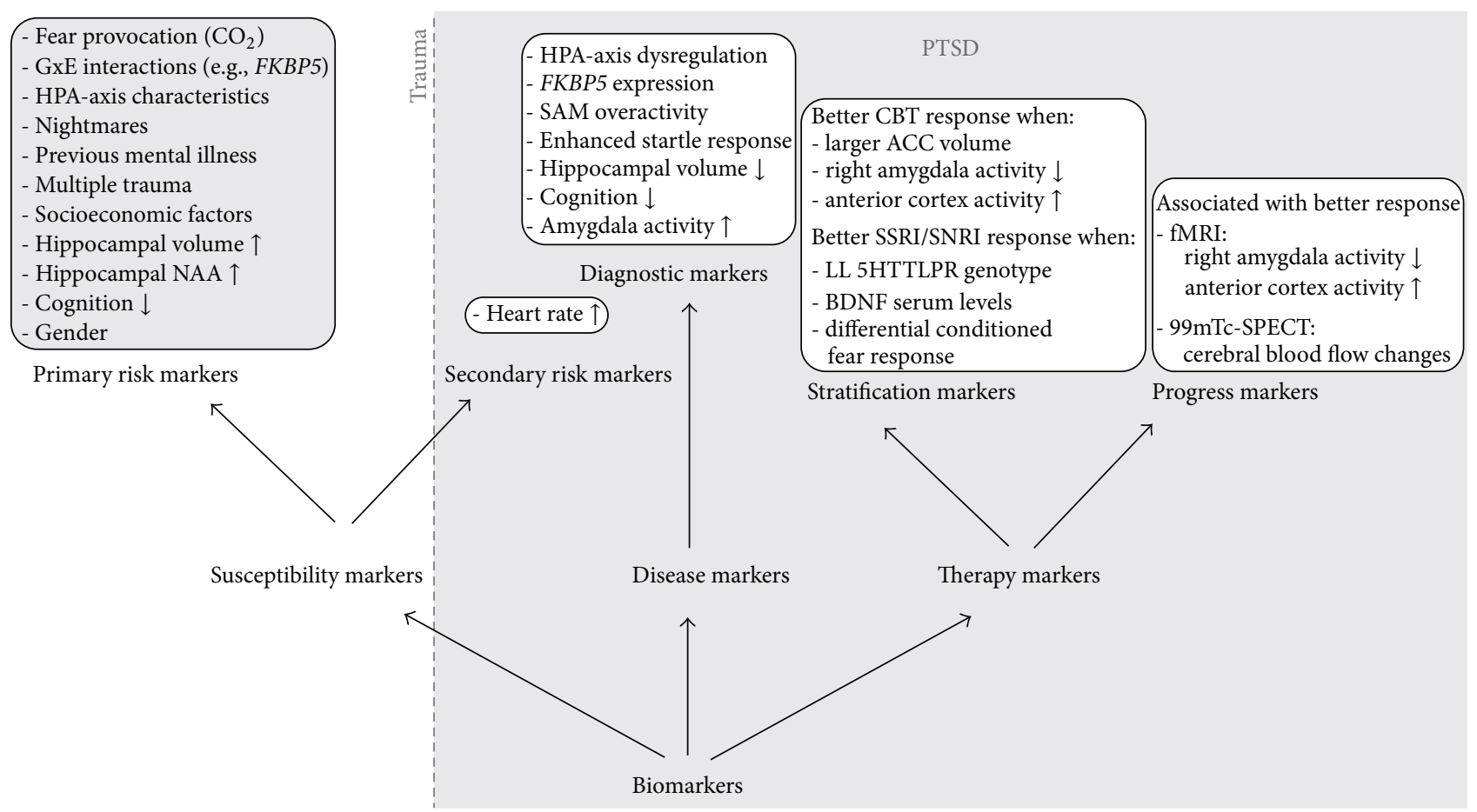

FIGURE 1: Schematic overview of PTSD biomarkers. Note that none of them is in clinical use. The most promising candidates are summarized in the Conclusion section.

categories of PTSD biomarkers is given in Figure 1. The term biomarker, as used in this paper, is neutral in that it neither indicates nor precludes a causal involvement in disease and therapy processes. If causality has been established, we talk about factors (e.g., arteriosclerosis represents a risk factor for stroke).

PTSD biomarkers outlined in this review comprise imaging, psychological, endocrine, and molecular biomarkers. The latter can be assessed on different molecular levels, namely, on the genetic level (DNA/SNP biomarkers), the gene expression level (RNA biomarkers), the level of proteins (peptide and protein biomarkers), and the level of the epigenome which programs the activity of our genome by several mechanisms, namely, DNA methylation, histone modifications, and RNA interference (epigenetic biomarkers). Imaging biomarkers are in general assessed by structural (i.e., magnetic resonance imaging, (MRI)), functional (i.e., functional MRI (fMRI)), single photon emission computed tomography (SPECT) or positron emission tomography (PET)), or metabolic (i.e., magnetic resonance spectroscopy (MRS)) methods.

PTSD therapy could be considerably improved: first, by the use of PTSD disease markers accelerating the diagnostic procedure, second, by biomarkers predicting the success of different therapeutic strategies before their application, and third, by markers allowing to monitor the course of therapy (Figure 1). Unfortunately, to date, there are still no generally accepted PTSD biomarkers in clinical use. The same applies to any other psychiatric disorder except for dementia for which several markers are in routine diagnostic use. Hence, all the PTSD biomarkers outlined in this review are potential PTSD biomarkers. With the aim of supporting the development of PTSD biomarkers, this review outlines the current state of research on biomarkers for PTSD susceptibility, PTSD diagnosis, and PTSD therapy by summarizing some of the most important findings.

Besides facilitating the diagnostic, therapeutic, and risk evaluation procedure, the identification of PTSD biomarkers promotes the elucidation of PTSD pathobiology and thereby possibly also the development of novel PTSD treatment options. There is currently no psychodrug that tackles PTSD core symptoms. PTSD patients would inter alia profit from a drug enhancing the effect of the stressful but essential exposure phase of PTSD psychotherapy. Currently, serotonin reuptake inhibitor (SSRI) antidepressants are considered as the gold standard of PTSD drug therapy. However, treatment results are disappointing since only $20-30 \%$ of SSRI-treated PTSD patients reach full remission [13].

While searching for PTSD biomarkers, we should recognize the fact that the majority of people confronted with a traumatic event does not develop PTSD. Hence it might be similarly important to identify resilience markers [11, $14,15]$, especially since resilience and vulnerability may represent extremes of the same dimension (e.g., low versus high expression levels of a distinct gene product). However, biomarkers of vulnerability and resilience may also originate from different dimensions with possible mutual interactions.

Most importantly, as PTSD is a heterogeneous diagnostic construct, a pathobiological feature common to all its different symptoms must not necessarily exist. Hence, searching 
for biomarkers for each of the three different PTSD symptom clusters would probably be a more reasonable and promising endeavor than searching for biomarkers reflecting the entire PTSD syndrome.

\section{Biomarkers of PTSD Susceptibility}

Susceptibility biomarkers, also termed as vulnerability biomarkers, comprise primary risk (and resilience) markers (Figure 1). Ideally, to search for PTSD susceptibility markers, pre/post assessments of individuals at high risk for trauma exposure, like for instance combat soldiers, should be implemented. Within the Dutch Armed Forces, a research group working with the University Medical Center Utrecht used such a longitudinal approach and searched for PTSD risk and resilience markers by comparing trauma-exposed Dutch soldiers with PTSD to those without PTSD and to healthy individuals without prior trauma exposure. Their analyses revealed that an elevated sensitivity of leukocytes for glucocorticoids and a high number of glucocorticoid receptors (GR) in peripheral blood monocytes prior to deployment predicted PTSD development [16, 17]. Moreover, low mRNA levels of the GR-inhibitor FK506 binding protein 5 (FKBP51) and high glucocorticoid-induced leucine zipper (GILZ) mRNA expression levels were independently associated with an increased risk for a high expression of postdeployment PTSD symptoms [18]. In addition, predeployment GR number predicted the increase in amygdala activity of healthy soldiers after deployment [19]. Hence, molecular regulators of the hypothalamus-pituitary adrenal (HPA)-axis activity, especially the GR and associated molecules, seem to predict individual PTSD susceptibility, at least in military cohorts. This conclusion is in line, first, with a trial showing that corticotropin-releasing hormone type 1 receptor gene (CRHR1) variants predict onset and course of PTSD in pediatric injury patients [20] and, second, with the results of a cross-sectional genetic candidate gene study in a US civilian cohort that revealed four SNPs of the FKBP5 gene to interact with the severity of child abuse as a predictor of adult PTSD symptoms [21]. Interestingly, it was recently discovered that one of the SNPs in FKBP5 increases the risk of developing stress-related psychiatric disorders in adulthood by allele-specific, childhood trauma-dependent DNA demethylation in functional glucocorticoid response elements of FKBP5 [22]. This demethylation was found to be linked to increased stress-dependent FKBP5 gene transcription associated with a long-term dysregulation of the stress hormone system and an elevated risk for developing stress-related psychiatric disorders like PTSD [22]. Thus, molecular constellations underlying gene $\mathrm{x}$ environment interactions indicate (as risk markers), if not contribute to (as risk factors), PTSD susceptibility in humans. Additional support for this well-grounded supposition arises from studies reporting that the low expression variant of the serotonin transporter gene increases the risk to develop PTSD under conditions of high stress (hurricane exposure) and low social support but not under low stress conditions $[23,24]$. That DNA methylation marks convey PTSD susceptibility is also alluded by a pre/post deployment study in a cohort of US military service members which revealed that the genomic repetitive elements LINE-1 and Alu are differentially methylated in predeployment samples of individuals with and without postdeployment PTSD [25]. Genetic polymorphisms associated with differences in PTSD susceptibility relate, besides FKBP5, inter alia to the catechol-O-methyltransferase (COMT) gene, the dopamine transporter and the dopamine receptor genes (for review see [11]).

Besides these molecular PTSD susceptibility markers, nonmolecular PTSD susceptibility markers have been postulated. For instance, in Dutch combat soldiers, predeployment nightmares were found to be associated with elevated PTSD susceptibility [26]. The authors suggest that nightmares are related to hampered fear extinction memory consolidation, which has been associated with REM sleep. Moreover, poor cognitive abilities have been often suggested as an important risk marker for PTSD development [27-30]. The same applies to the extent of pretrauma arousal which can be measured inter alia by fear-potentiated startle responses [31]. However, there is no general consensus in the literature about the validity of startle/arousal responses to sudden loud tones as risk markers of PTSD [32]. The situation might be different for other triggers of fear responses, as alluded by a trial using inhalation of $\mathrm{CO}_{2}$ provocation stimulus [33]. We suppose that the validity of fear responses as risk markers of PTSD seems to critically depend on the mode of provocation. Moreover, increased vulnerability to PTSD was repeatedly observed in individuals with a history of other mental disorders or previous trauma exposure [34]. Furthermore, the extent of the hippocampal volume prior to trauma exposure seems to negatively correlate with PTSD severity [35]. Furthermore, it is well accepted that gender affects PTSD susceptibility. Women have an almost twice as high prevalence for developing PTSD as men [36]. A recent clinical study revealed that there might be a genderspecific association between a genetic polymorphism (SNP) of the gene coding for the neuropeptide PAC1 (a receptor of the neuropeptide pituitary adenylate cyclase-activating peptide (PACAP)) and individual PTSD susceptibility [37]. Intriguingly, the $\mathrm{PACl}$ polymorphism resides in a putative estrogen response element, which may explain why this risk marker was valid only in women. Finally, heritability has been discussed as a PTSD vulnerability marker by some authors [38, 39]. In fact, a recent twin study found that heritable influences accounted for $46 \%$ of the variance in PTSD [40]. Besides heritability, an elevated prevalence of traumatic incidents may also contribute the higher PTSD prevalence in the offspring of PTSD patients [41].

Assessment of the individual susceptibility for developing PTSD can be accomplished not only before (risk marker for primary prevention or primary risk marker), but also in the early aftermath of the trauma (risk marker for secondary prevention or secondary risk marker; Figure 1). Shalev and colleagues identified a secondary risk marker for PTSD; they found increased heart rates [42-44] to predict PTSD susceptibility in the early aftermath of a traumatic event. Analyses in monozygotic twins discordant for combat exposure support the applicability of heart rate changes as secondary but not as primary risk markers [32]. 
Apart from these cardiovascular parameters, there were no other secondary risk markers reported so far, likely because searching for such biomarkers requires a large sample size and a prospective design. Studies aiming to identify secondary risk markers are further complicated by the existence of different subtypes of PTSD [45], especially by the delayed onset PTSD subtype which is characterized by an aboveaverage length of the symptom free episode before onset of PTSD symptoms [46].

\section{PTSD Disease Markers}

Disease markers comprise prognosis and diagnosis markers. There are numerous studies reporting on PTSD diagnosis markers which were identified upon analysis of the molecular and neural underpinnings of PTSD. In this chapter, we will briefly introduce some of the most prominent ones.

3.1. HPA-Axis Dysregulation. The already stated fact that HPA-axis regulators emerged, at least in certain populations, as PTSD susceptibility markers emphasizes the central role of the HPA-axis in PTSD. Some studies detected elevated levels of corticotropin-releasing hormone $(\mathrm{CRH})$ in cerebrospinal fluid (CSF) of PTSD patients $[47,48]$ and another study reported that $\mathrm{CSF} \mathrm{CRH}$ concentrations declined during exposure to a trauma-related audiovisual stimulus [49]. Findings regarding cortisol levels in PTSD patients are also inconsistent: while some authors found reduced cortisol levels in PTSD patients [50-52], others did not confirm these results and some of them even reported PTSD to be associated with hypercortisolemia $[47,53,54]$. To investigate HPA-axis responsivity in PTSD, clinical nonpharmacological and pharmacological stress tests were conducted. Some of these trials demonstrate that PTSD patients exhibit elevated salivary cortisol levels in response to laboratory stressors [55-57] while others found an enhanced plasma cortisol suppression after application of low dose dexamethasone [10, 58, 59].

Overall however, the majority of studies support the attenuation hypothesis of HPA-axis functioning in PTSD $[24,60,61]$. Possibly, the contrasting findings regarding HPAaxis activity in PTSD patients result from different specific psychiatric comorbidities (such as major depression and substance dependence disorder) and gender effects [24] and might also relate to the existence of different PTSD subtypes [45]. For instance, HPA axis regulation of patients suffering from the dissociative subtype of PTSD [62] might be different from other PTSD subtypes. This speculation is motivated by an analysis of a cohort of patients suffering from borderline personality disorder, a psychiatric disease resembling complex PTSD, which revealed that HPA-axis activity differed between patients with high and low frequency of dissociative symptoms [63]. Taken together, there is a strong need for systematic analyses of HPA-axis function and reactivity in large cohorts of PTSD patients to clarify the remaining inconsistencies.

As stated in the previous chapter, HPA-axis regulating cochaperone FKBP5 emerged as putative PTSD susceptibility marker. In a small study comparing individuals with and without PTSD in a group of Caucasians who all had been exposed to the 9/11 attack on New York City, several genes involved in glucocorticoid signaling were differentially expressed among individuals with current PTSD: mRNA levels of FKBP5 and the GR-inhibitor STAT5B were found to be reduced in PTSD patients [64]. Another study, performed in an African-American population, with baseline and postdexamethasone suppression cortisol levels and microarrayassessed gene expression levels as main outcome measures, showed that functional variants of FKBP5 polymorphisms are associated with biologically distinct subtypes of PTSD. [65]. In summary, there is evidence for FKBP5 to constitute both a potential PTSD susceptibility and a potential PTSD disease marker. To test the diagnostic applicability of FKBP5 as PTSD disease marker, future research needs to clarify whether alterations in FKBP5 mRNA levels and/or methylation patterns correlate with PTSD syndrome severity and whether they are specific for PTSD patients.

\subsection{Hyperdrive of the Sympathetic Adrenomedullary Sys-} tem. Numerous studies have provided convincing evidence for the presence of sympathetic adrenomedullary system (SAM) hyperreactivity in PTSD $[24,66]$ that is reflected inter alia in elevated urine noradrenaline levels [67] and, at least in a PTSD subgroup without comorbid depression, in elevated noradrenaline plasma levels [68]. It has been hypothesized that an excessively strong adrenergic response to the traumatic event might mediate the formation of pathologically long-lasting traumatic memories in PTSD [69]. Accordingly, adrenoreceptor blockers were reported to tackle PTSD symptoms, but not all studies were able to confirm this finding. Noradrenergic hyperdrive has been associated with several symptoms of PTSD, inter alia with nightmares and hyperarousal [70] and also with the PTSDassociated enhanced startle response that is widely accepted to mirror hyperarousal $[71,72]$. While hyperarousal in the absence of trauma-related stimuli and anxiety may reflect a general sensitization of the nervous system, reexperiencing symptoms like flashbacks and intrusions "maybe conceptualized within a fear conditioning framework" [24].

3.3. Enhanced Startle Response. The intensity of the startle response, a motor reflex, is probably the most robust potential PTSD disease marker to date. As mentioned above, the significance of startle and fear responses as PTSD risk markers is less clear. It was shown repeatedly that elevated startle occurs in both human PTSD patients [73-76] and rodents suffering from a PTSD-like syndrome [71,77-80]. It can be measured noninvasively, usually by assessment of the time till onset of a reflex motor reaction and the intensity of this reaction in response to a loud noise, unexpected touch, or air puff. Besides the already mentioned causal link to SAM hyperdrive, a larger startle response was found to be positively associated with cortisol levels and negatively associated with the steroid hormone dehydroepiandrosterone (DHEAS) [81]. Interestingly, cortisol suppression by dexamethasone reduces exaggerated startle responses in PTSD patients [82]. 
3.4. Impairments of Cognitive Functions. A number of studies report cognitive impairments in PTSD patients which become apparent in alterations in learning and memory [83-85]. These cognitive impairments have been assigned to frontotemporal areas exhibiting altered activity during both the encoding and retrieval phases of memory processing [86]. Moreover, it was hypothesized that PTSD-associated memory deficits result from excessive cortisol blood levels which probably lead to atrophy of the hippocampus $[87,88]$, an area known to play a pivotal role in learning and memory [89]. Numerous studies state that PTSD patients exhibit poorer attention and mnestic capabilities than trauma-exposed individuals without PTSD. To examine the long-term effects of PTSD on cognition, additional longitudinal follow-up studies in the elderly population are needed [90]. Taken together, PTSD patients exhibit several alterations in cognitive abilities, but so far no specific "PTSD cognition biomarker" can be extracted from the literature.

3.5. Hippocampal Volume Loss and Other Alterations of Brain Morphology and Function. There are many reports on brain region specific structural and functional alterations in PTSD patients and PTSD animal models. In PTSD patients, a volume reduction of the amygdala, the anterior cingulate cortex, the prefrontal cortex, and, most prominently, the hippocampus was described [91]. However, whereas some studies report a decreased hippocampal volume in PTSD patients [92-94] other studies did not replicate these findings [95-97]. In addition, reports on PTSD-associated lateralization of hippocampal volume loss are also controversial: while one meta-analysis reports such lateralization effects [98], others found none $[99,100]$. The meta-analysis by Woon and colleagues offers an explanation for this controversy since it reveals that hippocampal volume reduction seems to be more associated with the fact of trauma exposure than with the presence or intensity of PTSD [98]. A study comparing hippocampal volumes of twin pairs of which only one of the two siblings was exposed to combat and developed PTSD alludes that hippocampal volume loss is a risk marker for PTSD [35]. Further studies are clearly needed to clarify whether hippocampal volume loss is a PTSD susceptibility marker or PTSD disease marker or both.

The molecular underpinnings of the trauma-related hippocampal volume loss are still not fully understood [101]. Recent animal studies on consequences of chronic stress imply a prominent involvement of grey matter changes (e.g., dendritic atrophy and axon retraction; [102]). Accordingly, we recently observed a reduction of both presynaptic [103] and postsynaptic [79] proteins in the hippocampus of traumatized mice. We found that these changes could be prevented by chronic treatment with the SSRI-antidepressant fluoxetine [103]. It is tempting to assume that the biochemical and ultrastructural alterations underlying trauma-induced hippocampal volume loss can also be assessed in vivo using magnetic resonance spectroscopy (MRS). This approach is used to quantify $\mathrm{N}$-acetylaspartate (NAA), a marker of neuronal density. In line with the MRS studies, which have consistently reported lower NAA levels in the hippocampus of patients with PTSD $[24,104,105]$, our imaging studies performed in mice indicate that low NAA levels in the hippocampus before trauma predispose the animals to develop sustained PTSD-like symptoms [106]. This finding nourishes the speculation that reduction in hippocampal NAA levels might serve not only as PTSD disease but also as PTSD susceptibility marker for primary prevention in human patients.

The amygdala plays a crucial role in the detection of threat, fear learning, and fear expression [24]. Meta-analyses on the volume of the amygdala in PTSD patients revealed inconsistent results: some authors report smaller amygdalae volumes in PTSD patients [91] while others found no consistent differences [107]. Functional neuroimaging studies have reported exaggerated amygdala activation in response to trauma-related cues $[19,24]$.

A recent meta-analysis of studies analyzing structural differences in the brain of PTSD patients using voxelbased morphometry, shows structural deficits in gray matter compartments overlapping with brain networks of emotion processing, fear extinction, and emotional regulation [108].

\section{Biomarkers of PTSD Therapy}

PTSD therapy markers can be subdivided into stratification and progress markers (Figure 1). Ideally, therapy stratification markers should allow prediction of response of PTSD patients to certain therapeutic strategies thereby stratifying the PTSD patient population into different therapy responder types $[109,110]$. In contrast, therapy progress markers are useful for monitoring the therapy response. Studies aiming to identify PTSD therapy markers are relatively rare so far.

4.1. PTSD Therapy Progress Markers. We found three studies which identified putative PTSD therapy progress markers. Successful cognitive behavioral therapy was found to reduce the activity of the right amygdala and lead to an increase in the activity of the right anterior cingulate cortex in PTSD patients [111]. Moreover, Pagani and colleagues found 99mTc-HMPAO uptake differences (indicative of alterations in cerebral blood flow) between responders and patients not responding to EMDR treatment (eye movement desensitization and reprocessing therapy, a trauma-focused cognitive behavioral psychotherapeutic strategy). The authors described a trend towards normalization of tracer distribution after successful therapy [112]. In another study, PTSD symptom reduction was associated with larger rostral anterior cingulate (rACC volume; [113]).

4.2. PTSD Therapy Stratification/Prediction Markers. In the same study, responders to cognitive behavioral therapy were found to exhibit a larger rACC volume than nonresponders [113]. The same research group demonstrated that amygdala and ventral anterior cingulate activation predicts treatment response to cognitive behavior therapy in PTSD patients [113]. Besides these studies which analyzed the response to different psychotherapeutical strategies, there are a few trials searching for markers which allow for prediction of the response of PTSD patients to drug treatment. Differential 
conditioned fear response was found to predict outcome of treatment with the SNRI (serotonin noradrenalin reuptake inhibitor) antidepressant duloxetine in male veterans suffering from PTSD [114]. Recently, an association between a serotonin transporter gene promoter-region polymorphism and treatment response to the SSRI-antidepressant sertraline in PTSD was reported. The authors found the LL 5HTTLPR (serotonin-transporter-linked polymorphic region) genotype to be associated with greater responsiveness of PTSD to sertraline and with lower drop out due to adverse events, while the $\mathrm{S}$ allele was associated with a striking specificity for treatment nonresponse [115]. Moreover, in chronic PTSD patients, treatment response to escitalopram, another SSRI antidepressant, was demonstrated to be predicted by brain derived neurotrophic factor (BDNF) levels. Lower mean BDNF serum levels were associated with a greater decrease in PTSD symptoms over the course of the trial [116]. Synapsins, which we found to play a role in trauma-elicited hippocampal volume loss in mice, as detailed above, are known as mediators of BDNF-enhanced neurotransmitter release [117].

Besides molecular and imaging PTSD therapy stratification/prediction markers, performance of verbal memory and mixed-handedness were postulated to be suitable as putative PTSD treatment response markers [118, 119].

\section{Discussion}

Comparison of and principal conclusions from the so far performed studies on PTSD biomarkers are limited by different study designs, by varying diagnostic procedures, by the heterogeneity of the different types of traumatic events that PTSD patients were exposed to, and by the type of controls included. Some studies compare PTSD patients to healthy control individuals who had never been exposed to traumatic incidents before, others to PTSD-free but previously traumaexposed controls. That choosing between these two types of controls matters is inter alia shown by the review of Qureshi and colleagues who reported that the strength of the association of PTSD with cognitive impairment varied significantly with the control groups included in statistical analysis [90]. Studies comparing PTSD patients to nonexposed healthy controls do not enable differentiation between PTSD-associated biomarkers and biomarkers mirroring the response to the traumatic experience. On the other hand, comparisons of PTSD patients to trauma-exposed PTSD-free controls render it difficult to distinguish between diseaseversus resilience-related changes.

PTSD was found to be strongly associated with cardiovascular and pulmonary diseases [120, 121]. Confounding factors like these comorbid internal diseases, comorbid psychiatric disorders, medication, and consumption of illicit drugs are often difficult to control for-not only in PTSD biomarker studies but in almost every clinical trial. Ideally, for identification of PTSD biomarkers, a large group of PTSD patients should be compared to a large group of ageand sex-matched healthy controls who were exposed to the same (or at least to a similar) traumatic event as the PTSD patient cohort as well as to a matched non-exposed control group. These ideal conditions are hard to achieve and are usually approximated only by studies in military cohorts. Since, especially for clinical routine use, biomarkers should be applicable to the whole population and not only to a special subpopulation, studies searching for PTSD biomarkers in heterogenic civilian cohorts are strongly needed. C-reactive protein (CRP), which is globally used as infection marker in internal and general medicine, is an example for an almost ideal biomarker since its elevation robustly indicates acute systemic inflammation and is largely independent of gender, age, body mass index, and other individual variables [122].

So far, the search for biomarkers in PTSD and other psychiatric diseases was performed almost exclusively by comparison of a group of patients suffering from the disease studied to a healthy control group but not to groups of patients suffering from other psychiatric disorders. This type of analysis resulted inter alia in the identification of the putative PTSD susceptibility and disease marker FKBP5 [21, $22,64]$. Besides PTSD, FKBP5 has also been reported as a putative biomarker in mood disorders like major depression [123-125] as well as a biomarker of nonpsychiatric disorders like cancer [126-128]. Further studies comparing cohorts of patients suffering from different psychiatric disorders have to clarify whether FKBP5 is suitable as PTSD susceptibility and/or disease biomarker or whether it is a marker for a group of diseases associated with dysregulation of the HPAaxis or the GR pathway. The same specificity problem applies to the alterations in brain region activities and brain structures which have been associated with PTSD. For instance, hippocampal volume loss has not only been detected in PTSD patients but also in patients suffering from major depression $[101,129]$. This problem of biomarker specificity in the field of psychiatric disorders was addressed in a most recent genomewide association study in which over 30.000 patients suffering from five different major psychiatric disorders (i.e., attention deficit-hyperactivity disorder, schizophrenia, bipolar disorder, major depression, and autism spectrum disorder) were analyzed in comparison to about 28.000 controls. This huge trial revealed that SNPs in the genes of two calcium channel subunits, CACNA1C and CACNB2, associated not only with one but with a range of psychiatric disorders [130]. Hence, for identification of disorder-specific and robust PTSD susceptibility, disease, and therapy biomarkers, cohorts of patients suffering from different psychiatric diseases have to be included in comparative analyses.

Affective disorder-associated hippocampal volume loss has been causally related to changes in HPA-axis activity [129]. As mentioned, there is a growing body of evidence for HPA-axis hypoactivity in PTSD [24]. Future studies analyzing significantly larger cohorts of PTSD patients and healthy controls, under basal as well as under stress challenge conditions, are clearly needed to prove this hypothesis and to identify robust HPA-axis associated PTSD biomarkers. Undoubtedly, the two central stress axes, the HPA- and the SAM-axes, both play a major role in PTSD pathology. Elevated SAM activity has been postulated to promote the elevated startle response in PTSD. In fact, increased startle responses and/or the fearpotentiated startle reflex constitute the most robust putative PTSD biomarker to date with good reliability and specificity. 
First, numerous studies reported elevated startle responses in PTSD both in human patients $[73-75,131]$ and in animal models [77-80, 103], with only very few contradicting results $[132,133]$. Second, impaired fear inhibition assessed by fearpotentiated startle was found to be a biomarker of PTSD, but not of depression [134]. Since startle responses have so far been mainly analyzed in military cohorts of PTSD patients, studies analyzing startle responses in large cohorts of civilian PTSD patients are needed for validation.

Reports on PTSD therapy biomarkers are rare and certainly will have to be extended to allow general conclusions. However, some of them, especially those demonstrating that molecular markers predict response to SSRI and SNRI antidepressants, constitute promising starting points for future analyses.

Regulation and function of putative PTSD biomarkers identified in clinical studies can be analyzed in animal and cell culture models, as we demonstrated, for example, by showing that the putative PTSD biomarker FKBP5 significantly alters stress coping behavior and HPA-axis reactivity in mice [135]. Vice versa, studies in animal models can reveal novel putative PTSD biomarkers, like for instance our recent studies with which we identified a gross reduction in the expression levels of pre- and postsynaptic proteins like synapsin and GAP43 to be associated with hippocampal volume loss in mice suffering from a PTSD-like syndrome $[79,103]$. In particular the studies on the consequences of single prolonged stress [136] or predator scent exposure [77] have pioneered the field of PTSD animal models. Of high value is the distinction between responders and nonresponders in these models [77, 137,138 ] which not only allow to test novel pharmacological compounds, but also to search for biomarkers of PTSD vulnerability versus resilience in rats and mice. Interestingly, in our PTSD mouse model, the putative human PTSD susceptibility marker CRHR1 [20] was found to enhance the consolidation of remote fear memories in limbic brain structures of mice after their exposure to a traumatic foot shock. This enhancement was prevented by treatment with a CRHR1 antagonist in the first week after trauma [139]. Whether such potential novel PTSD drugs or novel putative PTSD biomarker candidate molecules identified by animal studies can be translated into the clinic should subsequently be analyzed in clinical trials.

The mentioned examples underscore that employing translational research approaches in PTSD biomarker research is a very promising endeavor that should be taken forward since, in contrast to biomarkers for example for internal disorders, no putative biomarker for PTSD or for any other psychiatric disorder except for dementia has yet progressed to the point of practical use [24].

\section{Conclusion}

The startle response is one of the most robust PTSD disease markers to date. Numerous studies have proven that the HPA-axis and the SAM axis are involved in PTSD, but reports on HPA activity in PTSD patients are inconsistent and require additional trials to determine whether PTSD patients exhibit an HPA-axis hypo- or overactivity or whether the HPA-axis is differentially regulated in distinct subpopulations of PTSD patients. The HPA-axis regulator FKBP5 emerged as primary PTSD risk and disease marker in several studies. Since this cochaperone was also described as biomarker of other affective disorders, further clinical trials have to clarify whether FKBP5 is a marker for PTSD or for affective disorders in general or whether FKBP5 is differentially regulated in different psychiatric diseases. The fact that none of the putative PTSD biomarkers reported so far is in clinical use stresses the urgent need for further PTSD biomarker studies with large sample sizes and for translational research approaches aiming to elucidate the molecular underpinnings of PTSD by combining clinical and animal studies.

\section{Conflict of Interests}

The authors declare no conflict of interests.

\section{References}

[1] American Psychiatric Association, Diagnostic and Statistical Manual of Mental Disorders DSM-IV-TR, American Psychiatric Association, 4th edition, 2000.

[2] R. C. Kessler, P. Berglund, O. Demler, R. Jin, K. R. Merikangas, and E. E. Walters, "Lifetime prevalence and age-of-onset distributions of DSM-IV disorders in the national comorbidity survey replication," Archives of General Psychiatry, vol. 62, no. 6, pp. 593-602, 2005.

[3] A. Maercker, S. Forstmeier, B. Wagner, H. Glaesmer, and E. Brähler, "Post-traumatic stress disorder in Germany. Results of a nationwide epidemiological study," Nervenarzt, vol. 79, no. 5, pp. 577-586, 2008.

[4] R. F. Mollica, K. McInnes, C. Poole, and S. Tor, "Dose-effect relationships of trauma to symptoms of depression and posttraumatic stress disorder among Cambodian survivors of mass violence," British Journal of Psychiatry, vol. 173, pp. 482-488, 1998.

[5] C. W. Hoge, C. A. Castro, S. C. Messer, D. McGurk, D. I. Cotting, and R. L. Koffman, "Combat duty in Iraq and Afghanistan, mental health problems, and barriers to care," The New England Journal of Medicine, vol. 351, no. 1, pp. 13-22, 2004.

[6] J. L. Price, "Findings from the National Vietnam Veterans' Readjustment Study," 2007, http://www.ptsd.va.gov/ professional/pages/vietnam-vets-study.asp.

[7] G. E. Richardson and P. J. Waite, "Mental health promotion through resilience and resiliency education," International Journal of Emergency Mental Health, vol. 4, no. 1, pp. 65-75, 2002.

[8] U. Schmidt, F. Holsboer, and T. Rein, "Epigenetic aspects of posttraumatic stress disorder," Disease Markers, vol. 30, no. 23, pp. 77-87, 2011.

[9] K. Domschke, "Patho-genetics of posttraumatic stress disorder," Psychiatria Danubina, vol. 24, pp. 267-273, 2012.

[10] R. Yehuda, S. L. Halligan, R. Grossman, J. A. Golier, and C. Wong, "The cortisol and glucocorticoid receptor response to low dose dexamethasone administration in aging combat veterans and holocaust survivors with and without posttraumatic stress disorder," Biological Psychiatry, vol. 52, no. 5, pp. 393-403, 2002.

[11] G. Wu, A. Feder, H. Cohen et al., "Understanding resilience," Frontiers in Behavioral Neuroscience, vol. 7, p. 10, 2013. 
[12] United Nations Environment Programme, International Labour Organisation, World Health Organization, International Program on Chemical Safety, Inter-Organization Programme for the Sound Management of Chemicals, and WHO Task Group on Environmental Health Criteria for Biomarkers in Risk Assessment: Validity and Validation, Biomarkers in Risk Assessment: Validity and Validation, World Health Organization, Geneva, Switzerland, 2001.

[13] W. Berger, M. V. Mendlowicz, C. Marques-Portella et al., "Pharmacologic alternatives to antidepressants in posttraumatic stress disorder: a systematic review," Progress in NeuroPsychopharmacology and Biological Psychiatry, vol. 33, no. 2, pp. 169-180, 2009.

[14] A. Feder, E. J. Nestler, and D. S. Charney, "Psychobiology and molecular genetics of resilience," Nature Reviews Neuroscience, vol. 10, no. 6, pp. 446-457, 2009.

[15] S. M. Southwick and D. S. Charney, "The science of resilience: implications for the prevention and treatment of depression," Science, vol. 338, pp. 79-82, 2012.

[16] M. van Zuiden, C. J. Heijnen, M. Maas et al., "Glucocorticoid sensitivity of leukocytes predicts PTSD, depressive and fatigue symptoms after military deployment: a prospective study," Psychoneuroendocrinology, vol. 37, pp. 1822-1836, 2012.

[17] M. van Zuiden, E. Geuze, H. L. D. M. Willemen et al., "Pre-existing high glucocorticoid receptor number predicting development of posttraumatic stress symptoms after military deployment," American Journal of Psychiatry, vol. 168, no. 1, pp. 89-96, 2011.

[18] M. van Zuiden, E. Geuze, H. L. D. M. Willemen et al., "Glucocorticoid receptor pathway components predict posttraumatic stress disorder symptom development: a prospective study," Biological Psychiatry, vol. 71, no. 4, pp. 309-316, 2012.

[19] E. Geuze, G. A. van Wingen, M. van Zuiden et al., "Glucocorticoid receptor number predicts increase in amygdala activity after severe stress," Psychoneuroendocrinology, 2012.

[20] A. B. Amstadter, N. R. Nugent, B.-Z. Yang et al., "Corticotrophin-releasing hormone type 1 receptor gene (CRHR1) variants predict posttraumatic stress disorder onset and course in pediatric injury patients," Disease Markers, vol. 30, no. 2-3, pp. 89-99, 2011.

[21] E. B. Binder, R. G. Bradley, W. Liu et al., "Association of FKBP5 polymorphisms and childhood abuse with risk of posttraumatic stress disorder symptoms in adults," Journal of the American Medical Association, vol. 299, no. 11, pp. 1291-1305, 2008.

[22] T. Klengel, D. Mehta, C. Anacker et al., "Allele-specific FKBP5 DNA demethylation mediates gene-childhood trauma interactions," Nature Neuroscience, vol. 16, pp. 33-41, 2013.

[23] D. G. Kilpatrick, K. C. Koenen, K. J. Ruggiero et al., “The serotonin transporter genotype and social support and moderation of posttraumatic stress disorder and depression in hurricaneexposed adults," American Journal of Psychiatry, vol. 164, no. 11, pp. 1693-1699, 2007.

[24] R. K. Pitman, A. M. Rasmusson, K. C. Koenen et al., "Biological studies of post-traumatic stress disorder," Nature Reviews Neuroscience, vol. 13, pp. 769-787, 2012.

[25] J. A. Rusiecki, L. Chen, V. Srikantan et al., "DNA methylation in repetitive elements and post-traumatic stress disorder: a casecontrol study of US military service members," Epigenomics, vol. 4, no. 1, pp. 29-40, 2012.

[26] S. van Liempt, M. van Zuiden, H. Westenberg, A. Super, and E. Vermetten, "Impact of impaired sleep on the development of ptsd symptoms in combat veterans: a prospective longitudinal cohort study," Depression and Anxiety, vol. 30, no. 5, pp. 469474, 2013.

[27] W. S. Kremen, K. C. Koenen, C. Boake et al., "Pretrauma cognitive ability and risk for posttraumatic stress disorder: a twin study," Archives of General Psychiatry, vol. 64, no. 3, pp. 361-368, 2007.

[28] C. R. Gale, I. J. Deary, S. H. Boyle, J. Barefoot, L. H. Mortensen, and G. D. Batty, "Cognitive ability in early adulthood and risk of 5 specific psychiatric disorders in middle age: the Vietnam Experience Study," Archives of General Psychiatry, vol. 65, no. 12, pp. 1410-1418, 2008.

[29] M. W. Gilbertson, L. A. Paulus, S. K. Williston et al., "Neurocognitive function in monozygotic twins discordant for combat exposure: relationship to posttraumatic stress disorder," Journal of Abnormal Psychology, vol. 115, no. 3, pp. 484-495, 2006.

[30] B. Schmand, J. H. Smit, M. I. Geerlings, and J. Lindeboom, "The effects of intelligence and education on the development of dementia. A test of the brain reserve hypothesis," Psychological Medicine, vol. 27, no. 6, pp. 1337-1344, 1997.

[31] N. Pole, T. C. Neylan, C. Otte, C. Henn-Hasse, T. J. Metzler, and C. R. Marmar, "Prospective prediction of posttraumatic stress disorder symptoms using fear potentiated auditory startle responses," Biological Psychiatry, vol. 65, no. 3, pp. 235-240, 2009.

[32] S. P. Orr, L. J. Metzger, N. B. Lasko et al., "Physiologic responses to sudden, loud tones in monozygotic twins discordant for combat exposure association with posttraumatic stress disorder," Archives of General Psychiatry, vol. 60, no. 3, pp. 283-288, 2003.

[33] M. J. Telch, D. Rosenfield, H. J. Lee, and A. Pai, "Emotional reactivity to a single inhalation of $35 \%$ carbon dioxide and its association with later symptoms of posttraumatic stress disorder and anxiety in soldiers deployed to Iraq," Archives of General Psychiatry, vol. 69, pp. 1161-1168, 2012.

[34] N. Breslau, H. D. Chilcoat, R. C. Kessler, and G. C. Davis, "Previous exposure to trauma and PTSD effects of subsequent trauma: results from the detroit area survey of trauma," American Journal of Psychiatry, vol. 156, no. 6, pp. 902-907, 1999.

[35] M. W. Gilbertson, M. E. Shenton, A. Ciszewski et al., "Smaller hippocampal volume predicts pathologic vulnerability to psychological trauma," Nature Neuroscience, vol. 5, no. 11, pp. 1242 1247, 2002.

[36] N. Breslau, "The epidemiology of trauma, PTSD, and other posttrauma disorders," Trauma, Violence, and Abuse, vol. 10, no. 3, pp. 198-210, 2009.

[37] K. J. Ressler, K. B. Mercer, B. Bradley et al., "Post-traumatic stress disorder is associated with PACAP and the PAC1 receptor," Nature, vol. 470, no. 7335, pp. 492-497, 2011.

[38] W. R. True, J. Rice, S. A. Eisen et al., "A twin study of genetic and environmental contributions to liability for posttraumatic stress symptoms," Archives of General Psychiatry, vol. 50, no. 4, pp. 257-264, 1993.

[39] K. C. Koenen, M. J. Lyons, J. Goldberg et al., "Co-twin control study of relationships among combat exposure, combat-related PTSD, and other mental disorders," Journal of Traumatic Stress, vol. 16, no. 5, pp. 433-438, 2003.

[40] C. E. Sartor, J. D. Grant, M. T. Lynskey et al., "Common heritable contributions to low-risk trauma, high-risk trauma, posttraumatic stress disorder, and major depression," Archives of General Psychiatry, vol. 69, no. 3, pp. 293-299, 2012.

[41] A. L. Roberts, S. Galea, S. B. Austin et al., "Posttraumatic stress disorder across two Generations: concordance and mechanisms 
in a population-based sample," Biological Psychiatry, vol. 72, no. 6, pp. 505-511, 2012.

[42] A. Y. Shalev, T. Sahar, S. Freedman et al., "A prospective study of heart rate response following trauma and the subsequent development of posttraumatic stress disorder," Archives of General Psychiatry, vol. 55, no. 6, pp. 553-559, 1998.

[43] A. Y. Shalev and S. Freedman, "PTSD following terrorist attacks: a prospective evaluation," American Journal of Psychiatry, vol. 162, no. 6, pp. 1188-1191, 2005.

[44] M. Y. Muraoka, J. G. Carlson, and C. M. Chemtob, “Twentyfour-hour ambulatory blood pressure and heart rate monitoring in combat-related posttraumatic stress disorder," Journal of Traumatic Stress, vol. 11, no. 3, pp. 473-484, 1998.

[45] C. J. Dalenberg, D. Glaser, and O. M. Alhassoon, "Statistical support for subtypes in posttraumatic stress disorder: the how and why of subtype analysis," Depression and Anxiety, vol. 29, no. 8, pp. 671-678, 2012.

[46] D. Horesh, Z. Solomon, G. Keinan, and T. Ein-Dor, “The clinical picture of late-onset PTSD: a 20-year longitudinal study of Israeli war veterans," Psychiatry Research, 2012.

[47] D. G. Baker, S. A. West, W. E. Nicholson et al., "Serial CSF corticotropin-releasing hormone levels and adrenocortical activity in combat veterans with posttraumatic stress disorder," American Journal of Psychiatry, vol. 156, no. 4, pp. 585-588, 1999.

[48] J. D. Bremner, J. Licinio, A. Darnell et al., "Elevated CSF corticotropin-releasing factor concentrations in posttraumatic stress disorder," American Journal of Psychiatry, vol. 154, no. 5, pp. 624-629, 1997.

[49] T. D. Geracioti Jr., D. G. Baker, J. W. Kasckow et al., "Effects of trauma-related audiovisual stimulation on cerebrospinal fluid norepinephrine and corticotropin-releasing hormone concentrations in post-traumatic stress disorder," Psychoneuroendocrinology, vol. 33, no. 4, pp. 416-424, 2008.

[50] M. Vythilingam, J. M. Gill, D. A. Luckenbaugh et al., "Low early morning plasma cortisol in posttraumatic stress disorder is associated with co-morbid depression but not with enhanced glucocorticoid feedback inhibition," Psychoneuroendocrinology, vol. 35, no. 3, pp. 442-450, 2010.

[51] D. Bremner, E. Vermetten, and M. E. Kelley, "Cortisol, dehydroepiandrosterone, and estradiol measured over 24 hours in women with childhood sexual abuse-related posttraumatic stress disorder," Journal of Nervous and Mental Disease, vol. 195, no. 11, pp. 919-927, 2007.

[52] R. Yehuda, B. Kahana, K. Binder-Brynes, S. M. Southwick, J. W. Mason, and E. L. Giller, "Low urinary cortisol excretion in holocaust survivors with posttraumatic stress disorder," American Journal of Psychiatry, vol. 152, no. 7, pp. 982-986, 1995.

[53] M. Maes, A. Lin, S. Bonaccorso et al., "Increased 24-hour urinary cortisol excretion in patients with post-traumatic stress disorder and patients with major depression, but not in patients with fibromyalgia," Acta Psychiatrica Scandinavica, vol. 98, no. 4, pp. 328-335, 1998.

[54] A. M. Lemieux and C. L. Coe, "Abuse-related posttraumatic stress disorder: evidence for chronic neuroendocrine activation in women," Psychosomatic Medicine, vol. 57, no. 2, pp. 105-115, 1995.

[55] J. D. Bremner, M. Vythilingam, E. Vermetten et al., "Cortisol response to a cognitive stress challenge in posttraumatic stress disorder (PTSD) related to childhood abuse," Psychoneuroendocrinology, vol. 28, no. 6, pp. 733-750, 2003.

[56] B. M. Elzinga, C. G. Schmahl, E. Vermetten, R. van Dyck, and J. D. Bremner, "Higher cortisol levels following exposure to traumatic reminders in abuse-related PTSD," Neuropsychopharmacology, vol. 28, no. 9, pp. 1656-1665, 2003.

[57] I. Liberzon, J. L. Abelson, S. B. Flagel, J. Raz, and E. A. Young, "Neuroendocrine and psychophysiologic responses in PTSD: a symptom provocation study," Neuropsychopharmacology, vol. 21, no. 1, pp. 40-50, 1999.

[58] R. Yehuda, D. Boisoneau, M. T. Lowy, and E. L. Giller Jr., "Dose-response changes in plasma cortisol and lymphocyte glucocorticoid receptors following dexamethasone administration in combat veterans with and without posttraumatic stress disorder," Archives of General Psychiatry, vol. 52, no. 7, pp. 583593, 1995.

[59] R. Yehuda, S. M. Southwick, J. H. Krystal, D. Bremner, D. S. Charney, and J. W. Mason, "Enhanced suppression of cortisol following dexamethasone administration in posttraumatic stress disorder," American Journal of Psychiatry, vol. 150, no. 1, pp. 83-86, 1993.

[60] R. Yehuda, "Current status of cortisol findings in post-traumatic stress disorder," Psychiatric Clinics of North America, vol. 25, no. 2, pp. 341-368, 2002.

[61] T. Jones and M. D. Moller, "Implications of hypothalamicpituitary-adrenal axis functioning in posttraumatic stress disorder," Journal of the American Psychiatric Nurses Association, vol. 17, no. 6, pp. 393-403, 2011.

[62] E. J. Wolf, M. W. Miller, A. F. Reardon, K. A. Ryabchenko, D. Castillo, and R. Freund, "A latent class analysis of dissociation and posttraumatic stress disorder: evidence for a dissociative subtype," Archives of General Psychiatry, vol. 69, pp. 698-705, 2012.

[63] D. Simeon, M. Knutelska, L. Smith, B. R. Baker, and E. Hollander, "A preliminary study of cortisol and norepinephrine reactivity to psychosocial stress in borderline personality disorder with high and low dissociation," Psychiatry Research, vol. 149, no. 1-3, pp. 177-184, 2007.

[64] R. Yehuda, G. Cai, J. A. Golier et al., "Gene expression patterns associated with posttraumatic stress disorder following exposure to the world trade center attacks," Biological Psychiatry, vol. 66, no. 7, pp. 708-711, 2009.

[65] D. Mehta, M. Gonik, T. Klengel et al., "Using polymorphisms in FKBP5 to define biologically distinct subtypes of posttraumatic stress disorder: evidence from endocrine and gene expression studies," Archives of General Psychiatry, vol. 68, no. 9, pp. 901910, 2011.

[66] J. R. Strawn and T. D. Geracioti Jr., "Noradrenergic dysfunction and the psychopharmacology of posttraumatic stress disorder," Depression and Anxiety, vol. 25, no. 3, pp. 260-271, 2008.

[67] T. R. Kosten, J. W. Mason, and E. L. Giller, "Sustained urinary norepinephrine and epinephrine elevation in post-traumatic stress disorder," Psychoneuroendocrinology, vol. 12, no. 1, pp. 1320, 1987.

[68] R. Yehuda, L. J. Siever, M. H. Teicher et al., "Plasma norepinephrine and 3-methoxy-4-hydroxyphenylglycol concentrations and severity of depression in combat posttraumatic stress disorder and major depressive disorder," Biological Psychiatry, vol. 44, no. 1, pp. 56-63, 1998.

[69] R. K. Pitman, "Post-traumatic stress disorder, hormones, and memory," Biological Psychiatry, vol. 26, no. 3, pp. 221-223, 1989.

[70] M. R. Dierks, J. K. Jordan, and A. H. Sheehan, "Prazosin treatment of nightmares related to posttraumatic stress disorder," Annals of Pharmacotherapy, vol. 41, no. 6, pp. 1013-1017, 2007.

[71] H. Anisman, "Sensitization in relation to posttraumatic stress disorder," Biological Psychiatry, vol. 70, no. 5, pp. 404-405, 2011. 
[72] A. Siegmund and C. T. Wotjak, "Toward an animal model of posttraumatic stress disorder," Annals of the New York Academy of Sciences, vol. 1071, pp. 324-334, 2006.

[73] R. W. Butler, D. L. Braff, J. L. Rausch, M. A. Jenkins, J. Sprock, and M. A. Geyer, "Physiological evidence of exaggerated startle response in a subgroup of Vietnam veterans with combatrelated PTSD," American Journal of Psychiatry, vol. 147, no. 10, pp. 1308-1312, 1990.

[74] S. P. Orr, N. B. Lasko, A. Y. Shalev, and R. K. Pitman, "Physiologic responses to loud tones in Vietnam veterans with posttraumatic stress disorder," Journal of Abnormal Psychology, vol. 104, no. 1, pp. 75-82, 1995.

[75] C. Grillon, C. A. Morgan III, M. Davis, and S. M. Southwick, "Effect of darkness on acoustic startle in Vietnam veterans with PTSD," American Journal of Psychiatry, vol. 155, no. 6, pp. 812817, 1998.

[76] R. Stam, "PTSD and stress sensitisation: a tale of brain and body. Part 1: human studies," Neuroscience and Biobehavioral Reviews, vol. 31, no. 4, pp. 530-557, 2007.

[77] H. Cohen, J. Zohar, and M. Matar, "The relevance of differential response to trauma in an animal model of posttraumatic stress disorder," Biological Psychiatry, vol. 53, no. 6, pp. 463-473, 2003.

[78] A. Armario, R. M. Escorihuela, and R. Nadal, "Long-term neuroendocrine and behavioural effects of a single exposure to stress in adult animals," Neuroscience and Biobehavioral Reviews, vol. 32, no. 6, pp. 1121-1135, 2008.

[79] Y. Golub, S. F. Kaltwasser, C. P. Mauch et al., "Reduced hippocampus volume in the mouse model of Posttraumatic Stress Disorder," Journal of Psychiatric Research, vol. 45, no. 5, pp. 650-659, 2011.

[80] P. R. Zoladz, M. Fleshner, and D. M. Diamond, "Differential effectiveness of tianeptine, clonidine and amitriptyline in blocking traumatic memory expression, anxiety and hypertension in an animal model of PTSD," Progress in NeuroPsychopharmacology \& Biological Psychiatry, vol. 44, pp. 1-16, 2013.

[81] C. Grillon, D. S. Pine, J. M. P. Baas, M. Lawley, V. Ellis, and D. S. Charney, "Cortisol and DHEA-S are associated with startle potentiation during aversive conditioning in humans," Psychopharmacology, vol. 186, no. 3, pp. 434-441, 2006.

[82] T. Jovanovic, J. E. Phifer, K. Sicking et al., "Cortisol suppression by dexamethasone reduces exaggerated fear responses in posttraumatic stress disorder," Psychoneuroendocrinology, vol. 36, no. 10, pp. 1540-1552, 2011.

[83] D. Brandes, G. Ben-Schachar, A. Gilboa, O. Bonne, S. Freedman, and A. Y. Shalev, "PTSD symptoms and cognitive performance in recent trauma survivors," Psychiatry Research, vol. 110, no. 3, pp. 231-238, 2002.

[84] M. W. Gilbertson, T. V. Gurvits, N. B. Lasko, S. P. Orr, and R. K. Pitman, "Multivariate assessment of explicit memory function in combat veterans with posttraumatic stress disorder," Journal of Traumatic Stress, vol. 14, no. 2, pp. 413-432, 2001.

[85] V. Roca and T. W. Freeman, "Complaints of impaired memory in veterans with PTSD," American Journal of Psychiatry, vol. 158, no. 10, pp. 1738-1739, 2001.

[86] M. D. Horner and M. B. Hamner, "Neurocognitive functioning in posttraumatic stress disorder," Neuropsychology Review, vol. 12, no. 1, pp. 15-30, 2002.

[87] R. M. Sapolsky, "Why stress is bad for your brain," Science, vol. 273, no. 5276, pp. 749-750, 1996.

[88] J. D. Bremner, "Does stress damage the brain," Biological Psychiatry, vol. 45, no. 7, pp. 797-805, 1999.
[89] L. R. Squire, "Memory and the hippocampus: a synthesis from findings with rats, monkeys, and humans," Psychological Review, vol. 99, no. 2, pp. 195-231, 1992.

[90] S. U. Qureshi, M. E. Long, M. R. Bradshaw et al., "Does PTSD impair Cognition beyond the effect of Trauma?" Journal of Neuropsychiatry and Clinical Neurosciences, vol. 23, no. 1, pp. 1628, 2011.

[91] A. Karl, M. Schaefer, L. S. Malta, D. Dörfel, N. Rohleder, and A. Werner, "A meta-analysis of structural brain abnormalities in PTSD," Neuroscience and Biobehavioral Reviews, vol. 30, no. 7, pp. 1004-1031, 2006.

[92] J. D. Bremner, "The relationship between cognitive and brain changes in posttraumatic stress disorder," Annals of the New York Academy of Sciences, vol. 1071, pp. 80-86, 2006.

[93] T. V. Gurvits, M. E. Shenton, H. Hokama et al., "Magnetic resonance imaging study of hippocampal volume in chronic, combat-related posttraumatic stress disorder," Biological Psychiatry, vol. 40, no. 11, pp. 1091-1099, 1996.

[94] J. D. Bremner, P. Randall, T. M. Scott et al., "MRI-based measurement of hippocampal volume in patients with combatrelated posttraumatic stress disorder," American Journal of Psychiatry, vol. 152, no. 7, pp. 973-981, 1995.

[95] N. Schuff, T. C. Neylan, M. A. Lenoci et al., "Decreased hippocampal $\mathrm{N}$-acetylaspartate in the absence of atrophy in posttraumatic stress disorder," Biological Psychiatry, vol. 50, no. 12, pp. 952-959, 2001.

[96] M. D. de Bellis, J. Hall, A. M. Boring, K. Frustaci, and G. Moritz, "A pilot longitudinal study of hippocampal volumes in pediatric maltreatment-related posttraumatic stress disorder," Biological Psychiatry, vol. 50, no. 4, pp. 305-309, 2001.

[97] C. Fennema-Notestine, M. B. Stein, C. M. Kennedy, S. L. Archibald, and T. L. Jernigan, "Brain morphometry in female victims of intimate partner violence with and without posttraumatic stress disorder," Biological Psychiatry, vol. 52, no. 11, pp. 1089-1101, 2002.

[98] F. L. Woon, S. Sood, and D. W. Hedges, "Hippocampal volume deficits associated with exposure to psychological trauma and posttraumatic stress disorder in adults: a meta-analysis," Progress in Neuro-Psychopharmacology and Biological Psychiatry, vol. 34, no. 7, pp. 1181-1188, 2010.

[99] M. E. Smith, "Bilateral hippocampal volume reduction in adults with post-traumatic stress disorder: a meta-analysis of structural MRI studies," Hippocampus, vol. 15, no. 6, pp. 798807, 2005.

[100] N. Kitayama, V. Vaccarino, M. Kutner, P. Weiss, and J. D. Bremner, "Magnetic resonance imaging (MRI) measurement of hippocampal volume in posttraumatic stress disorder: a metaanalysis," Journal of Affective Disorders, vol. 88, no. 1, pp. 79-86, 2005.

[101] B. Czéh and P. J. Lucassen, "What causes the hippocampal volume decrease in depression? Are neurogenesis, glial changes and apoptosis implicated?" European Archives of Psychiatry and Clinical Neuroscience, vol. 257, no. 5, pp. 250-260, 2007.

[102] M. S. Kassem, J. Lagopoulos, T. Stait-Gardner et al., "Stressinduced grey matter loss determined by MRI is primarily due to loss of dendrites and their synapses," Molecular Neurobiology, vol. 47, no. 2, pp. 645-661, 2013.

[103] L. Herrmann, I. A. Ionescu, K. Henes, Y. Golub, N. X. Wang, D. R. Buell et al., "Long-lasting hippocampal synaptic protein loss in a mouse model of posttraumatic stress disorder," PLoS One, vol. 7, Article ID e42603, 2012. 
[104] N. Schuff, T. C. Neylan, S. Fox-Bosetti et al., "Abnormal $\mathrm{N}$-acetylaspartate in hippocampus and anterior cingulate in posttraumatic stress disorder," Psychiatry Research, vol. 162, no. 2, pp. 147-157, 2008.

[105] A. Karl and A. Werner, "The use of proton magnetic resonance spectroscopy in PTSD research-Meta-analyses of findings and methodological review," Neuroscience and Biobehavioral Reviews, vol. 34, no. 1, pp. 7-22, 2010.

[106] A. Siegmund, S. F. Kaltwasser, F. Holsboer, M. Czisch, and C. T. Wotjak, "Hippocampal $\mathrm{N}$-acetylaspartate levels before trauma predict the development of long-lasting posttraumatic stress disorder-like symptoms in mice," Biological Psychiatry, vol. 65, no. 3, pp. 258-262, 2009.

[107] F. L. Woon and D. W. Hedges, "Hippocampal and amygdala volumes in children and adults with childhood maltreatmentrelated posttraumatic stress disorder: a meta-analysis," Hippocampus, vol. 18, no. 8, pp. 729-736, 2008.

[108] S. Kuhn and J. Gallinat, "Gray matter correlates of posttraumatic stress disorder: a quantitative meta-analysis," Biological Psychiatry, vol. 73, pp. 70-74, 2013.

[109] P. Elliott, D. Biddle, G. Hawthorne, D. Forbes, and M. Creamer, "Patterns of treatment response in chronic posttraumatic stress disorder: an application of latent growth mixture modeling," Journal of Traumatic Stress, vol. 18, no. 4, pp. 303-311, 2005.

[110] N. R. Stein, B. D. Dickstein, J. Schuster, B. T. Litz, and P. A. Resick, "Trajectories of response to treatment for posttraumatic stress disorder," Behavior Therapy, vol. 43, pp. 790-800, 2012.

[111] K. Felmingham, A. Kemp, L. Williams et al., "Changes in anterior cingulate and amygdala after cognitive behavior therapy of posttraumatic stress disorder," Psychological Science, vol. 18, no. 2, pp. 127-129, 2007.

[112] M. Pagani, G. Högberg, D. Salmaso et al., "Effects of EMDR psychotherapy on 99mTc-HMPAO distribution in occupationrelated post-traumatic stress disorder," Nuclear Medicine Communications, vol. 28, no. 10, pp. 757-765, 2007.

[113] R. A. Bryant, K. Felmingham, A. Kemp et al., "Amygdala and ventral anterior cingulate activation predicts treatment response to cognitive behaviour therapy for post-traumatic stress disorder," Psychological Medicine, vol. 38, no. 4, pp. 555561,2008

[114] D. E. Aikins, E. D. Jackson, A. Christensen, E. Walderhaug, S. Afroz, and A. Neumeister, "Differential conditioned fear response predicts duloxetine treatment outcome in male veterans with PTSD: a pilot study," Psychiatry Research, vol. 188, no. 3, pp. 453-455, 2011.

[115] D. Mushtaq, A. Ali, M. A. Margoob, I. Murtaza, and C. Andrade, "Association between serotonin transporter gene promoterregion polymorphism and 4 - and 12 -week treatment response to sertraline in posttraumatic stress disorder," Journal of Affective Disorders, vol. 136, no. 3, pp. 955-962, 2012.

[116] W. Berger, A. Mehra, M. Lenoci et al., "Serum brain-derived neurotrophic factor predicts responses to escitalopram in chronic posttraumatic stress disorder," Progress in NeuroPsychopharmacology and Biological Psychiatry, vol. 34, no. 7, pp. 1279-1284, 2010.

[117] J. N. Jovanovic, A. J. Czernik, A. A. Fienberg, P. Greengard, and T. S. Sihra, "Synapsins as mediators of BDNF-enhanced neurotransmitter release," Nature Neuroscience, vol. 3, no. 4, pp. 323-329, 2000.
[118] D. Forbes, J. Carty, P. Elliott et al., "Is mixed-handedness a marker of treatment response in posttraumatic stress disorder?: a pilot study," Journal of Traumatic Stress, vol. 19, no. 6, pp. 961-966, 2006.

[119] J. Wild and R. C. Gur, "Verbal memory and treatment response in post-traumatic stress disorder," British Journal of Psychiatry, vol. 193, no. 3, pp. 254-255, 2008.

[120] J. A. Boscarino, "Posttraumatic stress disorder and physical illness: results from clinical and epidemiologic studies," Annals of the New York Academy of Sciences, vol. 1032, pp. 141-153, 2004.

[121] C. Spitzer, S. Barnow, H. Völzke, U. John, H. J. Freyberger, and H. J. Grabe, "Trauma, posttraumatic stress disorder, and physical illness: findings from the general population," Psychosomatic Medicine, vol. 71, no. 9, pp. 1012-1017, 2009.

[122] I. Herzum and H. Renz, "Inflammatory markers in SIRS, sepsis and septic shock," Current Medicinal Chemistry, vol. 15, no. 6, pp. 581-587, 2008.

[123] E. B. Binder, D. Salyakina, P. Lichtner et al., "Polymorphisms in FKBP5 are associated with increased recurrence of depressive episodes and rapid response to antidepressant treatment," Nature Genetics, vol. 36, no. 12, pp. 1319-1325, 2004.

[124] E. B. Binder, "The role of FKBP5, a co-chaperone of the glucocorticoid receptor in the pathogenesis and therapy of affective and anxiety disorders," Psychoneuroendocrinology, vol. 34, no. 1, pp. S186-S195, 2009.

[125] M. Lekman, G. Laje, D. Charney et al., "The FKBP5-gene in depression and treatment response-an association study in the sequenced treatment alternatives to relieve depression (STAR*D) Cohort," Biological Psychiatry, vol. 63, no. 12, pp. 1103-1110, 2008.

[126] L. Li, Z. Lou, and L. Wang, "The role of FKBP5 in cancer aetiology and chemoresistance," British Journal of Cancer, vol. 104, no. 1, pp. 19-23, 2011.

[127] H. D. McKeen, D. J. Brennan, S. Hegarty et al., "The emerging role of FK506-binding proteins as cancer biomarkers: a focus on FKBPL," Biochemical Society Transactions, vol. 39, no. 2, pp. 663-668, 2011.

[128] J. Hou and L. Wang, "FKBP5 as a selection biomarker for gemcitabine and Akt inhibitors in treatment of pancreatic cancer," PLoS One, vol. 7, Article ID e36252, 2012.

[129] T. Frodl, A. Carballedo, M. M. Hughes et al., "Reduced expression of glucocorticoid-inducible genes GILZ and SGK-1: high IL-6 levels are associated with reduced hippocampal volumes in major depressive disorder," Translational Psychiatry, vol. 2, article e88, 2012.

[130] Cross-Disorder Group of the Psychiatric Genomics, "Identification of risk loci with shared effects on five major psychiatric disorders: a genome-wide analysis," The Lancet, vol. 381, no. 9875, pp. 1371-11379, 2013.

[131] R. Stam, "PTSD and stress sensitisation: a tale of brain and body Part 2: animal models," Neuroscience and Biobehavioral Reviews, vol. 31, no. 4, pp. 558-584, 2007.

[132] S. P. Orr, Z. Solomon, T. Peri, R. K. Pitman, and A. Y. Shalev, "Physiologic responses to loud tones in Israeli veterans of the 1973 Yom Kippur war," Biological Psychiatry, vol. 41, no. 3, pp. 319-326, 1997.

[133] C. Grillon, C. A. Morgan, S. M. Southwick, M. Davis, and D. S. Charney, "Baseline startle amplitude and prepulse inhibition in Vietnam veterans with posttraumatic stress disorder," Psychiatry Research, vol. 64, no. 3, pp. 169-178, 1996. 
[134] T. Jovanovic, S. D. Norrholm, N. Q. Blanding et al., "Impaired fear inhibition is a biomarker of PTSD but not depression," Depression and Anxiety, vol. 27, no. 3, pp. 244-251, 2010.

[135] C. Touma, N. C. Gassen, L. Herrmann et al., "FK506 binding protein 5 shapes stress responsiveness: modulation of neuroendocrine reactivity and coping behavior," Biological Psychiatry, vol. 70, no. 10, pp. 928-936, 2011.

[136] S. Yamamoto, S. Morinobu, S. Takei et al., "Single prolonged stress: toward an animal model of posttraumatic stress disorder," Depression and Anxiety, vol. 26, no. 12, pp. 1110-1117, 2009.

[137] H. Cohen, J. Zohar, M. A. Matar, Z. Kaplan, and A. B. Geva, "Unsupervised fuzzy clustering analysis supports behavioral cutoff criteria in an animal model of posttraumatic stress disorder," Biological Psychiatry, vol. 58, no. 8, pp. 640-650, 2005.

[138] V. Krishnan, M.-H. Han, D. L. Graham et al., "Molecular adaptations underlying susceptibility and resistance to social defeat in brain reward regions," Cell, vol. 131, no. 2, pp. 391-404, 2007.

[139] C. K. Thoeringer, K. Henes, M. Eder et al., "Consolidation of remote fear memories involves corticotropin-releasing hormone $(\mathrm{CRH})$ receptor type 1-mediated enhancement of AMPA receptor GluR1 signaling in the dentate gyrus," Neuropsychopharmacology, vol. 37, no. 3, pp. 787-796, 2012. 


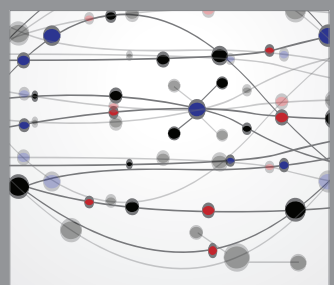

The Scientific World Journal
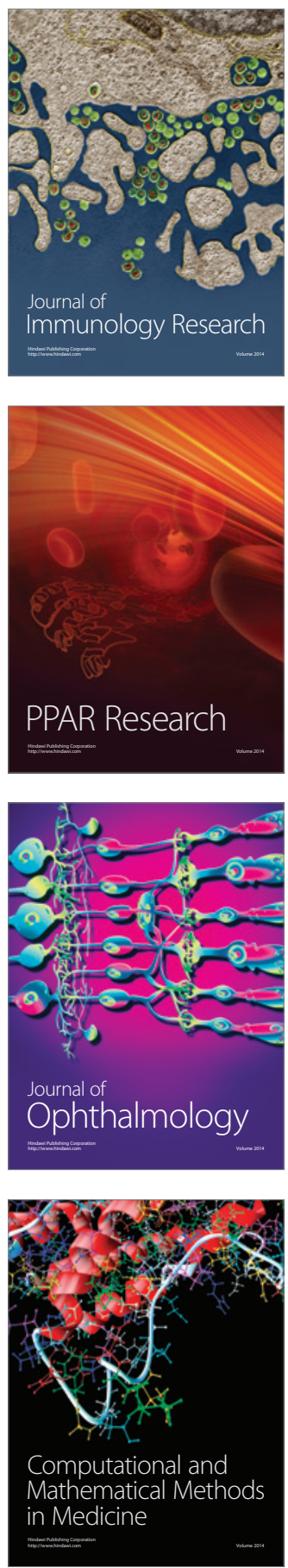

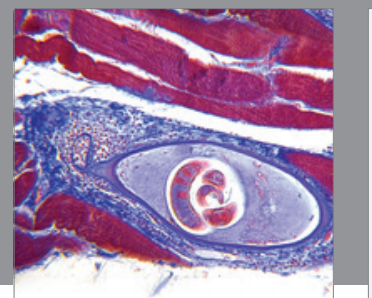

Gastroenterology

Research and Practice
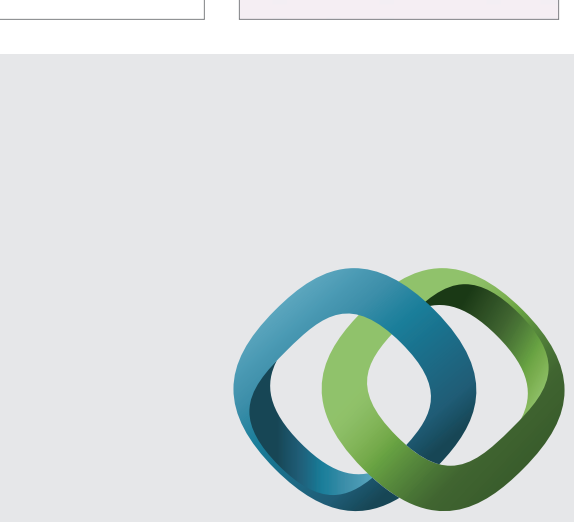

\section{Hindawi}

Submit your manuscripts at

http://www.hindawi.com
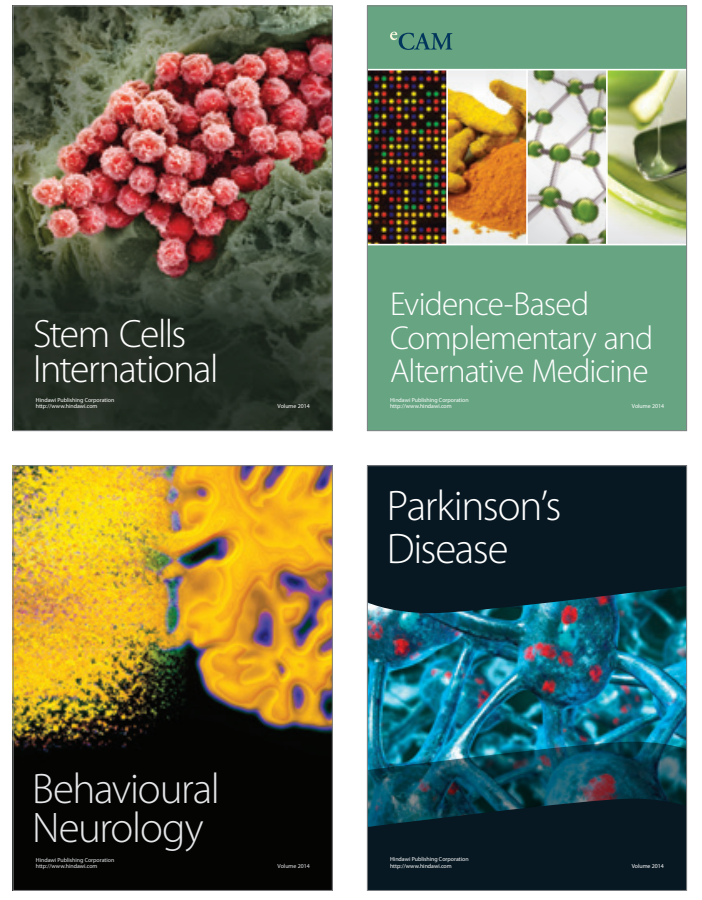
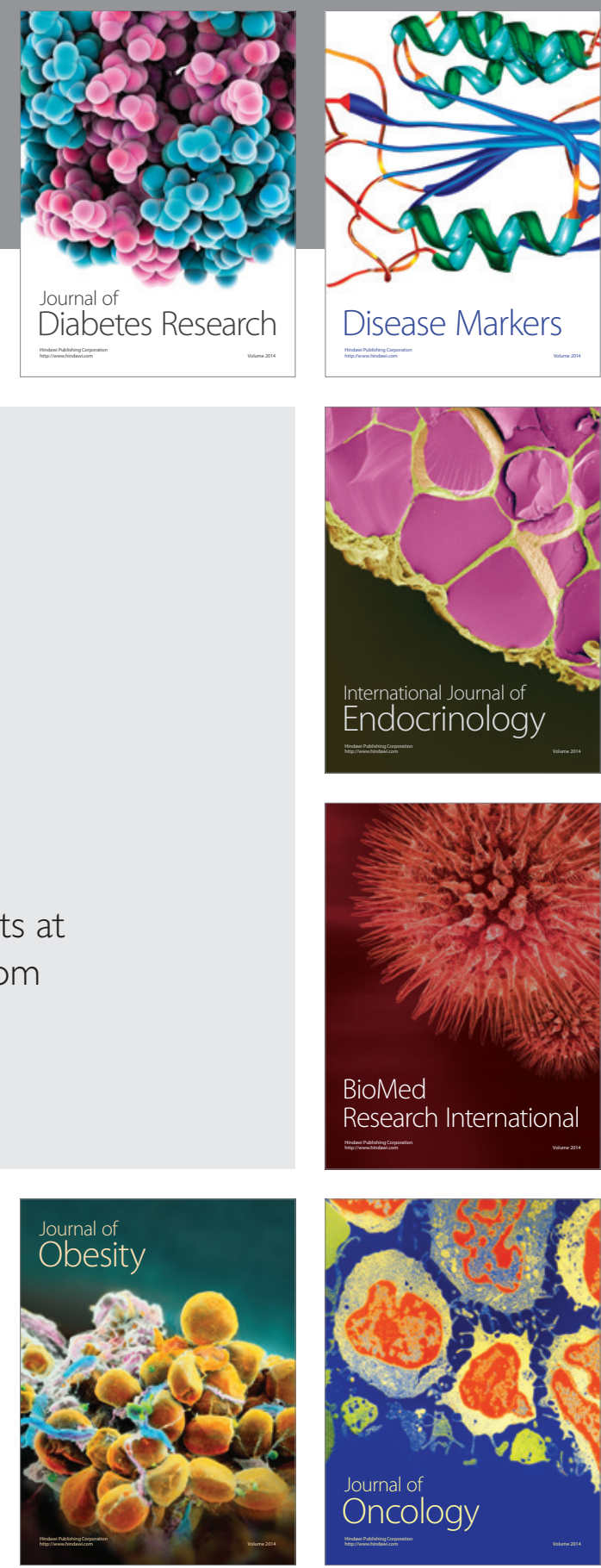

Disease Markers
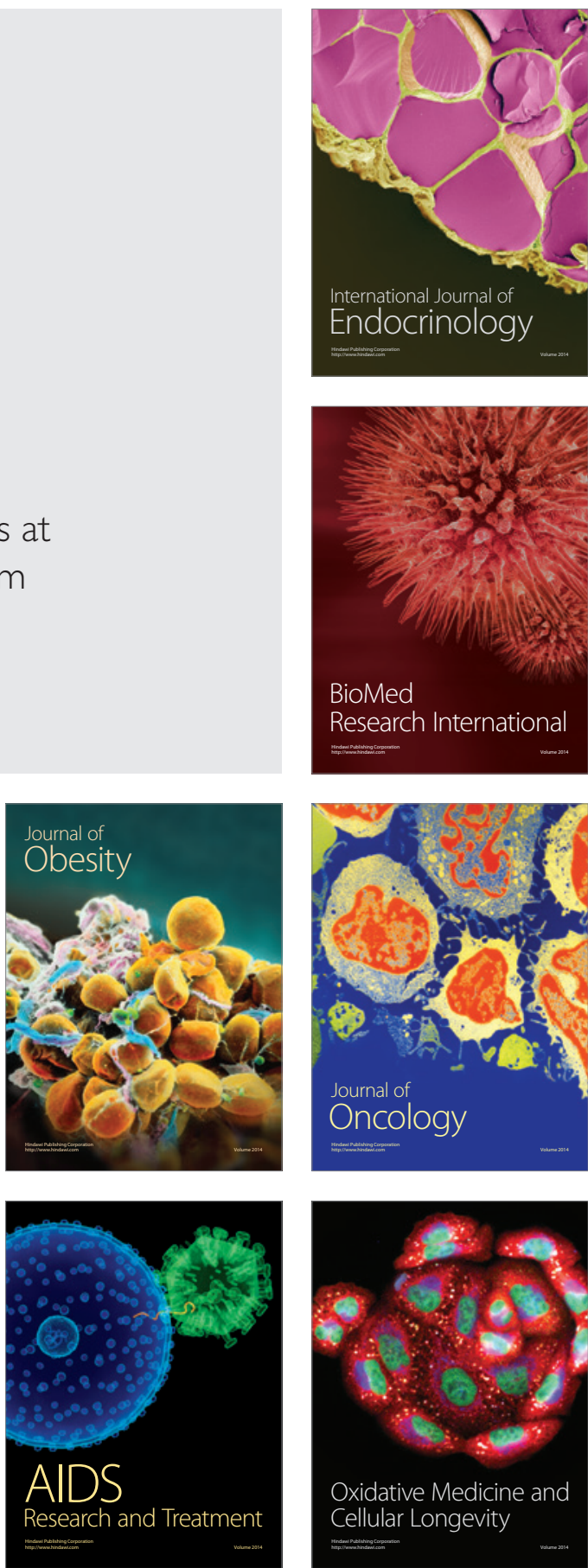